\title{
PENGEMBANGAN MODUL BIMBINGAN KE ARAH PENERIMAAN DIRI MELALUI BIMBINGAN KELOMPOK SISWA SMKN TUTUR PASURUAN
}

\author{
Dessy Ameliani Sasika Putri \\ Email: puth834@gmail.com
}

\begin{abstract}
Vocational students who are in their teens often have problems related to selfacceptance. the analysis conducted need assessment to students of class XI, it is known that students need information about self-acceptance in the form of guidance modules. Test performed by 2 expert BK. Prospective user test the products carried by 2 people vocational counselor. Data obtained from test experts and potential users test the product in the form of quantitative and qualitative data. Through the data collection techniques and grading scale acceptability of input / suggestions for improvements are written in pieces of advice available. The results of this research is the development of the guidance module toward selfacceptance SMK Negeri Tutur The oracle consists of four aspects, namely: (1) aspects of usability by expert 1 average of 3.00, a 4.00 second average; (2) aspects of the attractiveness by an average of 3.001 , expert 2 average 3.30; (3) aspects of practicality by an average of 3.161 , expert 2 average 3.83 ; (4) aspects of accuracy by an average of 3.001 , an average of 3.75 2. It can be concluded that the products have been developed very useful, very practical, very precise and very attractive, have acceptability in terms of theoretical Suggestion module development guidance toward self-acceptance is to be used as the media in providing services in the field of personal-social BK to increase self-acceptance vocational students.
\end{abstract}

Keywords: Module, self-acceptance, Group Guidance.

PENDAHULUAN

Banyak ahli psikologi mencermati karakteristik usia remaja dengan menggolongkan sebagai usia transisi dengan rendah kestabilan emosi, namun interaksi sosial dengan kelompok sebaya semakin meningkat. Masa remaja juga merupakan masa mencari identitas, berada dalam peralihan dengan status individu yang tak jelas dengan keraguan dan peranan. Remaja cenderung memandang dunia dan orang lain, dari kacamata sendiri sebagai yang diinginkan dan bukan sebagai mananya adanya (Hurlock, 1992: 207)
Pada umumnya individu khususnya remaja cenderung melihat dirinya sendiri sebagai kurang beruntung, sedangkan orang lain berada dalam pihak yang beruntung, bernasib baik, sukses dan sebagainya. Perilaku membanding-bandingkan diri memperlihatkan sikap yang tidak realistik dan memandang dan memahami diri hal ini merupakan indikasi bahwa remaja kurang memiliki penerimaan diri. Jika seseorang telah mampu melampui tahap proses penerimaan diri, maka penerimaan diri tersebut dapat menjadi energi yang 
sangat dahsyat untuk menggapai rencana masa depan. Sebaliknya, jika seseorang individu tersebut belum melalui tahapan penerimaan diri terhadap kondisi dirinya, maka dapat menjadi belenggu kehidupan dirinya.

Penerimaan diri merupakan salah satu aspek kepribadian yang berkembang karena belajar dan dipelajari. Penerimaan diri ditandai dengan adanya rasa percaya diri dan keberhargaan diri. Penerimaan diri mencakup penerimaan dari diri sendiri dan penerimaan dari orang lain, mampu menerima segala kelebihan dan kekurangan yang mereka miliki tanpa terbebani oleh perasaan menyalahkan diri sendiri.

Saat ini kegiatan bimbingan dan konseling di sekolah semakin dirasakan penting. Kewajiban sekolah adalah mengembangkan kepribadian seutuhnya termasuk keterbukaan. Melalui bimbingan pribadi mempunyai tanggung jawab besar untuk mengembangkannya, oleh sebab itu dalam menuai tugasnya, seorang konselor profesional membutuhkan media (Sadiman dkk, 2009:6) sebagai sarana memperlancar proses pemberian layanan bimbingan kepada siswa di sekolah. Sadiman dkk, (2009:18) menyatakan bahwa penggunaan media secara tepat dan bervariasi dapat mengatasi sikap pasif anak. Dalam hal ini media berguna untuk: 1) menimbulkan motivasi belajar, 2) memungkinkan interaksi langsung antar peserta didik dengan lingkungan dan kenyataan, 3) memungkinkan peserta didik belajar sendiri-sendiri menurut kemampuan dan minatnya. Siswa SMK telah mampu belajar mandiri jika sarana, fasilitas, dan materi tersedia secara memadai. Salah satu fasilitas untuk layanan bimbingan adalah modul bimbingan.

Berdasarkan observasi awal dan melakukan wawancara dengan guru BK di SMK Negeri Tutur sebagai tempat penelitian, modul bimbingan ke arah penerimaan diri belum di miliki. Selain itu layanan bimbingan ke arah penerimaan diri khususnya kelas XI juga belum diberikan oleh konselor, sehingga pemberian layanan bimbingan ke arah penerimaan diri dalam bentuk modul sangat dibutuhkan.

Berdasarkan hasil need assessment yang dilancarkan di SMK Negeri Tutur, menunjukkan bahwa dari 37 siswa yang telah mengisi angket need assessment menunjukkan 98,5\% siswa membutuhkan materi tentang penerimaan diri dari konselor, dari need assessment juga diketahui 98,5\% siswa belum pernah mendapatkan materi tentang penerimaan diri.

Berdasarkan permasalahan di atas, Peneliti tertarik memberikan solusi masalah penerimaan diri maka dikembangkan modul bimbingan ke arah penerimaan diri untuk siswa SMK. Modul bimbingan ke arah penerimaan diri untuk siswa SMK tersebut, merupakan pedoman bagi konselor sekolah dalam membantu siswa mengembangkan pengetahuan, pemahaman dan membantu siswa meningkatkan penerimaan diri. Selain itu, modul bimbingan ke arah 
penerimaan diri juga merupakan media bagi siswa dalam memperoleh wawasan dan pengetahuan tentang penerimaan diri.

\section{Penerimaan Diri}

Penerimaan diri adalah keinginan untuk memandang diri seperti adanya, dan mengenali diri sebagaimana adanya. Ini tidak berarti kurangnya ambisi karena masih adanya keinginankeinginan untuk meningkatkan diri, tetapi tetap menyadari bagaimana dirinya saat ini. Kemampuan untuk hidup dengan segala kelebihan dan kekurangan diri ini tidak berarti bahwa individu tersebut akan menerima begitu saja keadaannya, karena individu ini tetap berusaha untuk terus mengembangkan diri. individu dengan penerimaan diri akan mengetahui segala kelebihan dan kekurangan yang dimilikinya, dan mampu mengelolanya.

\section{Menurut Chaplin (2004:462),} penerimaan diri diartikan sebagai sikap seseorang yang merasa puas dengan diri sendiri, kualitas-kualitas, dan bakatbakatnya sendiri, serta pengakuan akan keterbatasan diri. Ada dua hal penting dalam arti penerimaan diri tersebut, pertama adanya perasaan puas terhadap apa yang telah dimiliki, kedua adanya pengakuan akan keterbatasan yang dimilikinya.

Menurut Rogers (dalam Hjelle dan Ziegelr, 1992:269) penerimaan diri terbagi menjadi dua, yaitu penerimaan dari diri sendiri dan penerimaan dari orang lain. Penerimaan dari lingkungan (keluarga atau orang lain) juga mempengaruhi penerimaan terhadap diri sendiri. Pada mulanya penerimaan dari orang lain akan berperan penting dalam mempengaruhi individu untuk menerima dirinya sendiri, akan tetapi pada selanjutnya yang paling berpengaruh terhadap penerimaan diri itu adalah individu yang bersangkutan. Individu harus bisa menerima segala kelebihan dan kekurangan yang mereka miliki tanpa terbebani oleh perasaan tanpa menyalahkan diri sendiri.

Penerimaan diri dapat dicapai apabila aspek-aspek dari diri dalam keadaan kongruen, dimana penerimaan diri individu sesuai dengan keadaan yang sebenarnya dan keadaan yang diinginkannya.

\section{Modul Bimbingan dan Konseling}

Menurut (Purwanto, dkk, 2007:9) modul merupakan bahan belajar yang dirancang secara sistematis berdasarkan kurikulum tertentu dan dikemas dalam bentuk satuan pembelajaran terkecil dan memungkinkan dipelajari secara mandiri dalam satuan waktu tertentu. Modul tersebut dirancang secara mudah agar memungkinkan siswa dapat mempelajari secara mandiri dan mudah dipahami.

Di dalam modul penerimaan diri ini mencakup beberapa hal, diantaranya, (1) menerima kelebihan dan kekurangan , merasa sejajar dengan orang lain, (2) membangun sikap positif terhadap diri 
sendiri dan merasa bahagia terhadap diri sendiri, (3) mampu bergaul dengan orang lain dan terbuka untuk dicintai dan dipuji, (4) bersikap tegas, menjadi diri sendiri, dan menentukkan nasib sendiri, (5) menertawai diri sendiri dengan mudah, mengenali dan mengurusi kebutuhan-kebutuhan sendiri.

\section{Bimbingan Kelompok}

Tujuan bimbingan kelompok adalah untuk memandirikan konseli dalam hal mengatur hidupnya, kepercayaan dirinya maupun dalam hal pengambilan keputusan. Tahap-tahap bimbingan kelompok menurut Prayitno (1995: 40) yaitu Tahap pembentukan, tahap peralihan, tahap kerja dan tahap pengakhiran. Selama proses bimbingan kelompok, siswa mendapat bimbingan guru BK baik berupa petunjuk secara lisan maupun petunjuk secara tertulis yang dituangkan dalam bentuk lembar kerja siswa yang mencakup unsur-unsur orisinalitas, kelancaran, fleksibilitas, dan elaborasi.

\section{METODE PENELITIAN}

Pengembangan ini menggunakan pendekatan dan pengembangan (research and development) yang dilakukan Borg dan Gall (dalam Sugiyono, 2010: 298), dengan alasan karena sesuai dengan tujuan yang hendak dicapai. Alasan lain penggunaan pendekatan penelitian dan pengembangan karena dianggap tepat untuk mengembangkan model pembelajaran yang tujuannya tidak sekedar menemukan profil implementasi atau praktik-praktik pembelajaran, namun lebih dari itu, yaitu mengembangkan model pembelajaran yang efektif dan mudah dalam penerapannya. Sesuai dengan kondisi dan kebutuhan nyata di sekolah.

Penelitian ini dilakukan dalam setting bimbingan kelompok dengan Subjek dalam penelitian ini adalah 10 orang siswa kelas XI ATRm 1 SMK Negeri Tutur yang memerlukan media modul bimbingan sebagai salah satu media informasi terkait tentang penerimaan diri. Alat pengumpulan data dilakukan dengan nontes berupa angket terbuka yang dikembangkan oleh peneliti yang bertujuan mengidentifikasi perlu tidaknya pengembangan layanan bimbingan dalam bentuk modul, informasi apa saja yang perlu dicantumkan dalam modul, dan bagaimana karakteristik modul bimbingan ke arah penerimaan diri. Uji coba produk dilakukan oleh 2 orang ahli media, dua orang ahli materi BK dan pengguna (siswa), selanjutnya hasil uji coba produk akan dilakukan analisa hasil.

\section{HASIL DAN PEMBAHASAN}

Penilaian Uji coba dilakukan untuk melihat kelayakan dan keberterimaan modul yang dikembangkan dan memenuhi kriteria akseptabilitas yaitu kegunaan, kemenarikan, kemudahan dan ketepatan. Uji coba akan dilakukan oleh ahli BK, guru BK/Konselor dan pengguna (siswa). 
Hasil Penilaian Ahli Bimbingan dan Konseling

\begin{tabular}{|l|l|l|l|l|}
\hline No. & $\begin{array}{l}\text { Aspek } \\
\text { Penilaian }\end{array}$ & $\begin{array}{l}\text { Jumlah } \\
\text { Item }\end{array}$ & $\begin{array}{l}\text { Penilaian } \\
\text { Ahli 1 }\end{array}$ & $\begin{array}{l}\text { Penilaian } \\
\text { Ahli 2 }\end{array}$ \\
\hline 1 & $\begin{array}{l}\text { Kegunaan } \\
\text { modul }\end{array}$ & 10 & 15 & 20 \\
\hline 2 & $\begin{array}{l}\text { Kemenrika } \\
\text { n modul }\end{array}$ & 6 & 9 & 10 \\
\hline 3 & $\begin{array}{l}\text { Kemudaha } \\
\text { n modul }\end{array}$ & 12 & 19 & 23 \\
\hline 4 & $\begin{array}{l}\text { Ketepatan } \\
\text { modul }\end{array}$ & 8 & 12 & 15 \\
\hline Jumlah & $\mathrm{n}=36$ & \multicolumn{2}{|c|}{$\sum \mathrm{x}=123$} \\
\hline
\end{tabular}

Dari hasil uji coba modul oleh ahli BK 1 dan ahli BK 2 diperoleh hasil bahwa penilaian oleh ahli BK 1 dan ahli BK 2 memberikan nilai rata-rata 3,41 , Dengan demikian, menurut penilaian dari ahli BK mengenai keberterimaan modul bimbingan ke arah penerimaan diri siswa SMK dapat dikatakan sesuai teori, baik/layak diterima atau layak digunakan. Pada angket terbuka untuk saran dan masukan dari ahli BK mengenai modul ini dikatakan bahwa modul bimbingan ke arah penerimaan diri siswa SMK ini menarik, namun ada beberapa hal yang perlu diperhatikan seperti: (1) bahasa lebih disesuaikan dengan kemampuan siswa SMK agar mudah dipahami (2) Gambar yang tidak sesuai perlu dirubah (3) pengetikan (spasi dan huruf perlu diteliti dan diperbaiki.

Hasil Penilaian Guru BK/Konselor

\begin{tabular}{|l|l|l|l|l|}
\hline No. & $\begin{array}{l}\text { Aspek } \\
\text { Penilaian }\end{array}$ & $\begin{array}{l}\text { Jumlah } \\
\text { Item }\end{array}$ & $\begin{array}{l}\text { Penilaian } \\
\text { Konselor } \\
1\end{array}$ & $\begin{array}{l}\text { Penilaian } \\
\text { Konselor } \\
2\end{array}$ \\
\hline 1 & $\begin{array}{l}\text { Kegunaan } \\
\text { modul }\end{array}$ & 10 & 19 & 16 \\
\hline 2 & $\begin{array}{l}\text { Kemenarikan } \\
\text { modul }\end{array}$ & 6 & 9 & 9 \\
\hline 3 & $\begin{array}{l}\text { Kemudahan } \\
\text { modul }\end{array}$ & 12 & 21 & 21 \\
\hline 4 & $\begin{array}{l}\text { Ketepatan } \\
\text { modul }\end{array}$ & 8 & 12 & 14 \\
\hline Jumlah & $\mathrm{n}=36$ & \multicolumn{2}{|c|}{$\sum \mathrm{x}=115$} \\
\hline
\end{tabular}

Selanjutnya, hasil uji coba modul oleh 2 guru BK/Konselor diperoleh hasil bahwa penilaian oleh konselor memberikan nilai rata-rata 3,19, yang berarti hasil uji coba modul yang dikembangkan berada pada kategori sesuai/ jelas/ mudah dipahami.. Pada angket terbuka yang berisi saran dan masukan dari kedua guru BK/Konselor terhadap modul bimbingan kea rah penerimaan diri siswa SMK memberikan komentar positif, bahwa modul penerimaan diri ini sangat bermafaat bagi siswa sebagai salah satu media yang dapat digunakan untuk memperoleh pemahaman terkait tentang penerimaan diri.

Hasil Penilaian Uji Pengguna (Siswa)

\begin{tabular}{|c|c|c|c|c|c|c|}
\hline \multirow{2}{*}{ No } & \multirow{2}{*}{$\begin{array}{l}\text { Aspek } \\
\text { Penilaian }\end{array}$} & \multirow{2}{*}{$\begin{array}{l}\text { Jumla } \\
\text { h Item }\end{array}$} & \multicolumn{4}{|c|}{$\begin{array}{l}\text { Frekuensi } \\
\text { Penilaian }\end{array}$} \\
\hline & & & 4 & 3 & 2 & 1 \\
\hline 1 & $\begin{array}{l}\text { Kemenarikan } \\
\text { modul }\end{array}$ & 30 & 20 & 10 & - & - \\
\hline
\end{tabular}




\begin{tabular}{|l|l|l|l|l|l|l|}
\hline 2 & $\begin{array}{l}\text { Kemudahan } \\
\text { modul }\end{array}$ & 60 & 38 & 22 & - & - \\
\hline & & $\begin{array}{l}\sum \mathrm{x} 1 \\
= \\
232\end{array}$ & $\begin{array}{l}\sum \mathrm{x} \\
2=\end{array}$ & $\begin{array}{l}\sum \mathrm{x} \\
3=\end{array}$ & $\begin{array}{l}\sum \mathrm{x} \\
4 \\
0\end{array}$ \\
& & $\mathrm{n}=90$ & \multicolumn{3}{|l|}{$\mathrm{x}=328$} \\
\hline Jumlah & &
\end{tabular}

Selanjutnya, hasil uji pengguna modul oleh siswa diperoleh hasil bahwa penilaian oleh siswa memberikan nilai rata-rata 3,64, yang berarti hasil uji coba modul yang dikembangkan berada pada kategori sangat sesuai/ jelas/ mudah dipahami. Pada angket terbuka yang berisi saran dan masukan dari siswa terhadap modul bimbingan ke arah penerimaan diri siswa SMK memberikan komentar positif, bahwa modul penerimaan diri ini sangat menarik dan bahasanya mudah dipahami.

\section{SIMPULAN DAN SARAN}

Modul bimbingan ke arah penerimaan diri ini dimaksudkan untuk menambah pemahaman tentang penerimaan diri. Siswa dikatakan paham apabila mengetahui keadaan dirinya sendiri. Siswa yang memahami dirinya dengan baik akan memiliki penerimaan yang baik pula. Produk akhir pengembangan terdapat komponen evaluasi yang berupa skala penerimaan diri. Skala penerimaan diri tersebut untuk mengkur tingkat penerimaan diri siswa. Modul penerimaan diri ini terdiri dari 5 penggalan yaitu (1) perasaan sederajat, (2) Percaya Kemampuan Diri, (3) orientasi keluar diri, berpendirian dan (5) menyadari keterbatasan. Berdasarkan penilaian uji ahli modul bimbingan ke arah penerimaan diri siswa SMK Modul bimbingan ke arah penerimaan diri untuk siswa SMK memiliki nilai sangat berguna, sangat praktis, sangat tepat, dan sangat menarik, memiliki keberterimaan teoritis berdasarkan kriteria akseptabilitas.

Saran penelitian adalah modul bimbingan kea rah penriaan diri ini hendaknya dapat digunakan sebagai acuan dalam pengembangan media BK dan dapat dijadikan sebagai salah satu alternatif pemberian layanan informasi kepada siswa khususnya terkait penerimaan diri.

\section{DAFTAR RUJUKAN}

Chaplin, J.P. 2004. Kamus Lengkap Psikologi. Jakarta: PT Raja Grafindo Persada

Depdiknas.2006.Standar Kompetensi Pelajaran Bahasa Indonesia SMA dan

MA.Jakarta:Departemen

Pendidikan Nasional

Hjelle,Larry A. dan Ziegler,Daniel S. 1992.PersonalityTheory:Basic

Assumptions, Research, and Applications.Tokyo:Mc Graw Hill,Inc

Hurlock,E.B. 1992. Adolescance development ( $4^{\text {th }}$ ed).Tokyo: Mc Graw-Hill Kogakusha,Ltd

Hurlock,E.B.1992.Psikologi

Perkembangan.Jakarta.Gramed ia

Hurlock.

1974.http://guea31.wordpress.c om 2010/11/02/dampak dari adanya penerimaan diri 
Joint Committee on Standards For Educational Evaluation. 1991. Standards For Evaluations of Educational Program Project and Materia. Terjemahan oleh Rasdi Ekosiswoyo. . Ikip Semarang Press.

Paramita,R.(2012).Pengaruh

Penerimaan Diri terhadap

Penyesuaian Diri Penderita LUPUS.Skripsi.Sarjana.Univers itas Airlangga Surabaya

Prayitno. 1995. Layanan Bimbingan Dan Konseling Kelompok Dasar Dan Profil. Jakarta:Rineka Cipta

Purwanto,dkk.2007. Pengembangan Modul. Jakarta. Kencana

Sadiman,A.S., dkk. 2009.Media Pendidikan. Jakarta:PT.Raja Grafindo

Sugiyono. 2010. Metode Penelitian Kuantitatif, Kualitatif dan $R \& D$. Bandung:Alfabeta. 